\title{
LITERATURA, FORMACIÓN Y REPÚBLICA. ANDRÉ MAUROIS Y EL INSTINTO DE FELICIDAD BURGUÉS (PRIMERA PARTE)*
}

\author{
Literature, education and Republic. André Maurois and the \\ instinct of bourgeois happiness (First part)
}

\section{Raquel de la Arada Acebes ${ }^{\S}$; Jordi Garcia Farrero ${ }^{\delta}$ y Conrad Vilanou Torrano $^{\varphi}$}

Fecha de recepción: 08/06/2016 • Fecha de aceptación: 28/10/2016

«La vida es demasiado corta para que sea mezquina»

(André Maurois)

Resumen. En este artículo se analizan las relaciones entre la literatura y los ideales formativos de André Maurois (1885-1967). Se revisan sus años de formación a la sombra del filósofo Alain, su profesor en el Liceo de Ruan. Se destaca la presencia de elementos militares en su universo pedagógico hasta el punto de que la obra educativa de la Tercera República francesa (1870-1940) se entiende a la luz de la combinación entre la inteligencia y las armas, esto es, entre el liceo y el cuartel. Maurois viajó por los Estados Unidos y, preocupado por el ambiente de crisis de la década de los años veinte y treinta, se inspiró en el mariscal Hubert Lyautey, a fin de determinar las características del arte de mandar que, junto al arte de pensar, de amar, de trabajar y de envejecer, configuran los distintos aspectos del Arte de vivir (1939) que se inscribe en la mejor de las tradiciones pedagógicas francesas (Montaigne, Rousseau, Alain), que destaca la importancia del oficio de vivir. En última instancia, y desde una posición burguesa amante

\footnotetext{
$\S$ Departament de Teoria i Història de l'Educació. Facultat d'Educació. Universitat de Barcelona. Paseo del Valle Hebrón, 171. Edificio Llevant. 08035 Barcelona. España. rdelarada@ub.edu.

${ }^{\delta}$ Departament de Teoria i Història de l'Educació. Facultat d'Educació. Universitat de Barcelona. Paseo del Valle Hebrón, 171. Edificio Llevant. 08035 Barcelona. España. jgarciaf@ub.edu.

${ }^{\varphi}$ Departament de Teoria i Història de l'Educació. Facultat d'Educació. Universitat de Barcelona. Paseo del Valle Hebrón, 171. Edificio Llevant. 08035 Barcelona. España. cvilanou@ub.edu.

" La investigación que ha dado lugar a estos resultados ha sido impulsada por RecerCaixa. En atención a la extensión de este estudio, el presente trabajo se articula en dos partes, la primera de las cuales aparece en este número de la revista, de modo que la segunda queda pendiente de publicación para un próximo número. Agradecemos a los responsables de Historia y Memoria de la Educación las atenciones recibidas para poder publicar este estudio en su integridad.
}

Cómo citar este artículo: Arada Acebes, Raquel de la; Garcia Farrero, Jordi; y Vilanou Torrano, Conrad. «Literatura, formación y república. André Maurois y el instinto de felicidad burgués (Primera parte)", Historia y Memoria de la Educación, 5 (2017): 157-190. 
del orden, Maurois pretende que el ser humano lleve una vida feliz, en sintonía con los valores republicanos heredados de la Revolución de 1789. En suma, Maurois fue un intelectual que combinó tradición y modernidad en un mundo cambiante que, después de la Primera Guerra Mundial (1914-1918), dejó atrás las aparentes seguridades de la Belle Époque, sin perder de vista el horizonte de la felicidad humana al margen de cualquier consideración metafísica. Su obra tuvo una gran repercusión en España antes y después de la Guerra Civil, circunstancia que este trabajo intenta poner de manifiesto, con lo cual contribuyó decididamente a cambiar la moral pública de nuestro país.

Palabras clave: André Maurois; Tercera República Francesa; Arte de mandar; Oficio de vivir; Arte de vivir

Abstract. This article describes the relationship between literature and the educational ideals of André Maurois (1885-1967). After a review of his formative years in the shadow of the philosopher Alain, who was his teacher at Rouen Lyceum, the paper goes on to highlight the presence of military elements in his educational universe The extent of this influence can be seen in the fact that, after the Dreyfus affair, the educational work undertaken during the Third French Republic (1870-1940) is best understood in the light of the combination between intelligence and weapons, that is, between the lyceum and the garrison. Maurois, who traveled throughout the United States, was concerned about the atmosphere of crisis in the decade of the twenties and thirties, and took inspiration from Marshal Hubert Lyautey in order to comprehend the characteristics of the art of leadership. This skill, together with the art of thinking, the art of loving, the art of working, and the art of growing old, give shape to the various aspects of Maurois' The Art of Living (1939), which fits nicely in the best of French pedagogical traditions (Montaigne, Rousseau, Alain) and highlights the importance of the task of living. Ultimately, and from a bourgeois stance embracing order, Maurois intended for the human being to lead a happy life, in line with the Republican values inherited from the 1789 Revolution. In short, he was an intellectual who combined tradition and modernity in a changing world that, after World War I (1914-1918), left behind the false securities of the Belle Époque. An author who never forgot the perspective of human happiness beyond any metaphysical consideration, Maurois' work had a great impact in Spain, before and after the Civil War. This paper expounds on the influence he exerted and the way he contributed decisively to changing the public sense of morality in our country.

Key words. André Maurois; Third French Republic; Art of Leadership; Job of Living; Art of Living 
No cabe duda de que la literatura de André Maurois (1885-1967) gozó de gran predicamento durante la primera mitad del siglo pasado, alargándose su influencia hasta el mítico 1968 que marcó un punto de inflexión en los gustos de los lectores. Aunque sus libros se continuaron imprimiendo en España, a través de grandes proyectos editoriales como el de Plaza \& Janés y el de Círculo de Lectores, después de mayo del 68 otra generación de escritores surgió en el horizonte, y Maurois —como tantos otros- quedó relegado a un segundo plano, diluyéndose su presencia hasta desaparecer casi completamente en la actualidad, a pesar de haber alcanzado la distinción de académico en 1938. Sólo de tarde en tarde se escucha alguna voz que reivindica su obra, tal como hizo recientemente Valentí Puig, desde las páginas de El País, en la edición de Cataluña del 19 de junio de 2015, en que contrastaba la claridad de la escritura de Maurois frente a la actual tendencia académica hacia la transgresión. Aunque su maestro Alain (Émile Chartier, 1868-1951) sugirió que se dedicara a la novela, y no al ensayo, lo cierto es que Maurois cultivó la literatura de ficción —sus novelas, empero, siempre poseen un trasfondo autobiográfico- y también el ensayo, en especial el género biográfico del que llegó a ser un auténtico maestro junto a otros especialistas como Stefan Zweig y Emil Ludwig. Él mismo reconoce que creyó tener vocación de moralista y novelista, que descolló en el campo de la biografía y la historia.

Es de notar que bajo la influencia de Lytton Strachey, autor de Victorianos eminentes (1918), a quien trató personalmente, Maurois elaboró espléndidas biografías como la que dedicó al político conservador Benjamín Disraeli, judío asimilado como él, sin olvidar las de Shelley y Byron, Voltaire y Napoleón, Víctor Hugo y Chateaubriand. Y, por ello, no nos pueden extrañar las siguientes palabras de Maurois: «Strachey es, sin duda, al mismo tiempo, un historiador exacto, pero ha sabido dotar su materia de una forma perfecta y para él ha sido esa forma lo esencial». ${ }^{1}$

Estas palabras extraídas de su tratado sobre Aspectos de la biografía, que se compone de un ciclo de seis conferencias pronunciadas en el Trinity College de Cambridge, en mayo de 1928 bajo los auspicios de la

\footnotetext{
${ }^{1}$ André Maurois, «Aspectos de la biografía», Obras Completas. IV (Barcelona: Plaza \& Janés, 1962), 1188.
} 
Fundación Clark, pueden ser ampliadas con el siguiente fragmento de la misma obra:

El método de Strachey carece de pesadez. No critica, no juzga, sólo expone. Su procedimiento es el de los grandes humoristas. El autor jamás aparece. Se pasea detrás de la reina, detrás del cardenal Manning, detrás del General Gordon; imita sus gestos, sus vicios de lenguaje y obtiene, así, excelentes efectos cómicos. ${ }^{2}$

Según esta perspectiva, las biografías de los personajes radiografiados por Maurois - que contaron con mucha aceptación y repetidas ediciones-incluyen una clara intención didáctica, y así adquieren una función ejemplar. «La mejor enseñanza moral, la única eficaz, es el ejemplo». ${ }^{3}$ En realidad, su obra fue traducida desde el primer momento, de manera que en la década de los cincuenta (con reediciones posteriores hasta finales de los sesenta) la editorial Plaza \& Janés preparó unas Obras Completas en siete volúmenes. Sin ser exhaustivas, lo cierto es que recogen lo más sustancial de la producción de Maurois, una edición precedida por un estudio introductorio de María Luz Morales, directora de La Vanguardia durante la Guerra Civil. Además, en 1968, se da a conocer en español el libro de Jacques Suffel sobre André Maurois, que había aparecido en París en 1963, con notas y comentarios del mismo autor, que ilustran y complementan las reflexiones del biógrafo de nuestro personaje. ${ }^{4} \mathrm{Se}$ trata del único estudio riguroso sobre Maurois que ha sido traducido, si bien se han sucedido otros trabajos monográficos sobre su obra, ya sea en lengua francesa o inglesa. ${ }^{5}$

\footnotetext{
${ }^{2}$ Maurois, «Aspectos de la biografía», 1194.

${ }^{3}$ André Maurois, «Destinos ejemplares», Obras Completas. V (Barcelona: Plaza \& Janés, 1968), 741.

${ }^{4}$ Jacques Suffel, André Maurois con notas de André Maurois (Barcelona: Ediciones G. P., 1968), 51 [André Maurois avec des remarques par André Maurois. Portrait-dialogue (Paris: Flammarion, 1963). Ediciones G. P. formaba parte del grupo editorial Plaza \& Janés, que se encargó de la versión española de las obras completas de nuestro autor].

${ }^{5}$ Entre los estudios universitarios sobre André Maurois, aparecidos después de la biografía de Jacques Suffel, citamos los siguientes títulos: Judith Kauffmann, Aspects d'André Maurois biographe (Paris: Association des Publications près les Universités de Strasbourg, Diffusion Ophrys, 1980) y Jack Kolbert, The Worlds of André Maurois (Selinsgrove, Susquehanna University Press/London and Toronto, Associated University Press, 1980), amén de los trabajos de Dominique Bona y Thierry Jacques Laurent que son citados en el lugar correspondiente de esta serie de dos artículos.
} 
Precisamente, María Luz Morales —una de las pioneras del periodismo femenino en España- no dudó en señalar que «el signo de Marte ha pesado de manera curiosa sobre la trayectoria de Maurois. Y por tres veces ha marcado inesperado rumbo a su destino». ${ }^{6}$ En concreto, la escritora gallega se refería a la guerra franco-prusiana (1870) y a las dos guerras mundiales del siglo Xx, de las que Maurois fue testigo privilegiado. Por el momento quede registrado este vínculo de la vida de Maurois con la guerra, que puede ser visto también como una constante en una vida que - aunque se movió en el ámbito civil— mostró sus simpatías por la esfera castrense. "La milicia —en el más profundo y amplio sentido del vocablo- le encuentra siempre alerta, siempre dispuesto a la completa entrega». ${ }^{7}$ En último término, la milicia también formó parte del ethos republicano francés, aspecto que se hizo más palpable en los momentos de la Primera Guerra Mundial, en la tragedia de 1940 y durante la crisis de la Cuarta República (1958).

\section{UN INTELECTUAL REPUBLICANO Y REFORMISTA}

Sabido es que Maurois se dio a conocer a raíz de la aparición de Los silencios del Coronel Bramble (1918), novela ambientada en la Gran Guerra, que le obligó a ocultar su verdadero nombre, Émile Salomon Wilhelm Herzog, bajo el seudónimo de André Maurois. Podemos añadir que optó por André en honor a un pariente caído durante la guerra y que Maurois corresponde a una población de Flandes, escenario bélico de aquella contienda. Al margen de la anécdota, Los silencios del Coronel Bramble constituyen un elogio al sistema de vida británico que encuentra una base sólida en el espíritu deportivo inglés. Al mismo tiempo, Maurois muestra su distanciamiento respecto a la cultura alemana que, a fin de cuentas, fue la responsable de que su familia tuviese que abandonar Alsacia.

En otras palabras, Maurois más que un anglófilo fue un anglómano que mostró sus simpatías por el mundo anglosajón, primero Inglaterra, y más tarde, los Estados Unidos, un país donde detecta la lucha por la igualdad, la ausencia de los prejuicios que existían en Europa y el respeto

\footnotetext{
' María Luz Morales, «André Maurois. Vida y obras», en Obras Completas. I (Barcelona: Plaza \& Janés, 1966), XII.

${ }^{7}$ Morales, «André Maurois. Vida y obras», XVII.
} 
a la disciplina, en medio de una atmósfera conservadora. Se comprende entonces que, a raíz del convencimiento de que América es la hija mayor de Europa, realizase diversas estancias en los Estados Unidos que visitó en fechas sucesivas. La primera en 1927; la segunda en 1931, cuando profesó en Princeton; la tercera en 1933, que aprovechó para escribir La salvación de Norteamérica; la cuarta en 1939, cuando predijo certeramente la actitud que seguirían los Estados Unidos durante la Segunda Guerra Mundial, a la que se incorporarían con retraso a fin de poderse armar convenientemente; la quinta, y más larga, corresponde a su exilio en Nueva York entre 1940 y 1942, época en que redactó su Historia de los Estados Unidos; en 1946 volvió de nuevo, fecha en la que elaboró un diario que se tradujo al castellano y, por último, en $1960 .^{8}$

Bien mirado, Maurois representa el tipo de intelectual reformista identificado con los valores de la Tercera República Francesa, aquella Francia surgida de la guerra franco-prusiana de 1870 que acarreó la pérdida de Alsacia y Lorena, territorios que pasaron a formar parte del recién constituido Segundo Imperio alemán. Así lo describe Maurois:

El 18 de enero de 1871 fue proclamado en Versalles, en la galería de los Espejos, el Imperio alemán. Bismarck triunfaba sobre Richelieu: los tratados de Westfalia estaban rotos. Este triunfo no debía ser duradero, mas en ese momento Alemania parecía dueña de Europa. ${ }^{9}$

Se dibuja, por consiguiente, una identidad política que ve los regímenes de la Cuarta (1946-1958) y Quinta —establecida a partir de la Consti-

\footnotetext{
${ }^{8}$ Entre los libros de Maurois dedicados a los Estados Unidos, y vertidos al español, en ediciones al margen de las Obras Completas, citamos los siguientes: La salvación de Norteamérica (Barcelona: Lara, 1944), Estados Unidos (Barcelona: Luis de Caralt, 1945) y Diario (Estados Unidos 1946) (Buenos Aires: Espasa-Calpe, 1947). Por su parte, la Historia de los Estados Unidos se incluyó en el volumen segundo de sus Obras Completas, dedicado a la historia (Barcelona: Plaza \& Janés, 1961). Tal como él mismo comenta, se trata de un libro análogo al que publicó en 1937 sobre la Historia de Inglaterra, con una voluntad encaminada a divulgar los principios del liberalismo político. Así, en el prólogo, a la Historia de los Estados Unidos recoge las siguientes palabras: «En ambas obras he intentado ofrecer al lector un bosquejo del desarrollo de una civilización y de un sistema político. Creo que tales trabajos son útiles, no precisamente porque aportan a los eruditos elementos nuevos, sino porque ordenan, bajo la forma de una narración continua y relativamente sencilla, numerosos documentos que jamás han sido traducidos del inglés». Hay que añadir que la Historia de Inglaterra cuenta con una edición reciente (Barcelona: Ariel, 2007), lo que trasluce la capacidad observadora y sintética de André Maurois y, por extensión, la actualidad de su obra.
}

${ }^{9}$ André Maurois, «Historia de Francia», Obras Completas. II (Barcelona: Plaza \& Janés, 1961), 513-514. 
tución de 1958 - repúblicas francesas como un continuo con la Tercera república $(1870-1940) .{ }^{10}$

De hecho, su familia de ascendencia judía asimilada, se trasladó con su industria textil - y con los centenares de familias obreras correspondientes-de Alsacia hasta Normandía, de modo que optaron por permanecer fieles a Francia, renunciando a pertenecer al imperio alemán que acababa de nacer bajo la égida de Prusia que se había impuesto bélicamente a daneses (1864), austriacos (1866) y franceses (1870). Su familia estaba integrada por empresarios, pequeños burgueses de provincias, que vivían alejados de París y, por tanto, de las pretensiones de la haute bourgeoisie de la capital. En el fondo, observaba un estricto rigor moral que recuerda - según el mismo Maurois- el carácter puritano de los cuáqueros, aspecto que, probablemente, enlaza con la espiritualidad jansenista de Port-Royal. ${ }^{11}$ Ahora bien, este ambiente no coincide con el puritanismo que dominaba en Nueva Inglaterra, según describió Henry James en su novela Los europeos (1878), cuya erosión captó en Princeton durante sus años de docencia poco después de la crisis del 29. ${ }^{12}$

Una de las características de la literatura de Maurois estriba en el sentido pedagógico de su producción, aspecto que siguiendo los pasos de Goethe se confirma en distintos lugares de su obra, no sólo en Un arte de vivir (1939), sino muy especialmente en la Lettre ouverte à un jeune homme (1966), que preparó cuando había cumplido ochenta años. Este interés por la formación también se deja sentir en sus biografías, que contemplan — como la de Balzac- capítulos destinados a analizar los años de aprendizaje de sus personajes. Así se explica su apego por Henry Adams, de modo que Maurois hacía leer a sus alumnos americanos el libro que el escritor norteamericano dedicó a su propia formación, «donde éste expone que su verdadera educación no se la debe ni a la escuela, ni a Harvard, sino a la vida». ${ }^{13}$

En realidad, nos encontramos ante una defensa del ethos republicano pero un tanto periférica, desde los viñedos del Midi, o bien desde las in-

\footnotetext{
${ }^{10}$ André Maurois, Lettre ouverte à un jeune homme (Paris: Éditions Albin Michel, 1966), 144.

${ }^{11}$ André Maurois, Memorias (Barcelona: Aymá, 1944), 37.

12 André Maurois, Tierra de promisión (Barcelona, José Janés editor, 1949), 205-207.

${ }^{13}$ Maurois, Diario (Estados Unidos 1946), 60 [La educación de Henry Adams ha sido considerada una de las mejores obras de la literatura norteamericana. Hay traducción: Barcelona: Alba Editorial, 2001$].$
} 
dustrias del noreste, sobre el supuesto de que la República no era únicamente una cuestión de la casta política («caste de politiciens») sino algo que incumbía a todos los ciudadanos. ${ }^{14}$ Uno de los personajes de la novela El círculo de familia (1932) expresa la siguiente opinión: «En tiempo de Balzac, una provincia tal vez fuera un mundo aparte; pero no es así ya. Las mujeres que aquí viven leen los mismos libros, ven las mismas obras y van a los mismos conciertos que las de París». ${ }^{15}$

De alguna manera, sus novelas autobiográficas — sobre todo Bernard Quesnay (1926), y en menor medida El círculo de familia (1932) - alertan sobre las preocupaciones e intereses de aquel mundo industrial de provincias, que vivía un conjunto de convenciones y apariencias.

Por su parte, en Tierra de promisión (1946) refleja el ambiente industrial parisino, con el trasfondo de la industria automovilística de los grandes magnates del ramo como los hermanos Renault. Ahora bien, Maurois no quedó satisfecho con todas las novelas que escribió a modo de compensación. En este sentido, únicamente muestra su beneplácito por tres títulos, a saber, Bernard Quesnay (1926), Climas (1928) y El circulo de familia (1932), mientras que El instinto de felicidad (1934), Tierra de promisión (1946) y Las rosas de septiembre (1956) no le acabaron de complacer. ${ }^{16}$

Sea como fuere, sus estudiosos coinciden en señalar que el biógrafo, el historiador y el moralista supera con creces al Maurois novelista que, a pesar de todo, levanta acta con sus ficciones literarias de una época ciertamente convulsa. De la misma manera que Balzac dio cuenta y razón de la época de la Restauración, Maurois retrata una atmósfera social salpicada por una crisis - la de entreguerras- no sólo política y económica, sino también axiológica, es decir, de valores. En este punto conviene traer a colación la obra de Balzac Fisiología del matrimonio (1829), un libro para algunos frívolo e inmoral, que alcanzó un gran éxito y que fue incluido más tarde en la Comedia humana. En estas páginas, Balzac abordó la cuestión del matrimonio como una guerra conyugal donde afloran el adulterio y los hijos ilegítimos. Es probable que las cifras

\footnotetext{
${ }^{14}$ Henry Leyret, La République et les politiciens. Lettres de Province (Paris: Bibliothèque-Charpentier, 1909), VIII.

${ }^{15}$ André Maurois, El círculo de familia (Barcelona: Ediciones Edita, 1951), 103.

${ }^{16}$ Suffel, André Maurois con notas de André Maurois, 83-84.
} 
que Balzac maneja sean excesivas, pero recuerda que entonces existía en Francia «una masa flotante de un millón quinientas mil personas ilegítimas al menos». ${ }^{17}$ Bien mirado, Balzac y Maurois buscan acabar con esta realidad bélica. Así, en la biografía que nuestro autor dedicó a Balzac, se leen las siguientes palabras: «En resumen, el matrimonio es un combate, una guerra civil que exige armas y una estrategia y en donde la victoria (es decir, la libertad) es para el más diestro». ${ }^{18}$ A lo largo de toda su vida, y espoleado por su propia experiencia, Maurois persigue que la paz conyugal se imponga a través de una búsqueda de la felicidad, un bien que únicamente se consigue después de grandes sacrificios, o, lo que es lo mismo, después del «esfuerzo continuo para crearla». ${ }^{19}$

De este afán por fotografiar las costumbres sociales se desprenden imágenes como la que refleja que no estaba bien visto que las niñas fuesen enviadas al Liceo de Ruan, de modo que eran educadas por niñeras e institutrices inglesas con una presencia significativa de los valores tradicionales y victorianos. Miss Binker -institutriz de Clara Forgeaud, protagonista de Tierra de promisión (1946), personaje que recuerda a Simone- es una excelente muestra de lo que decimos.

Ahora bien, el mundo de aquella burguesía de provincias contrastaba con la vida sofisticada de París, que Maurois también frecuentaba durante su juventud en sus viajes semanales a la capital por motivos profesionales, relacionados con los intereses de la industria familiar. Allí, a orillas del Sena, sin olvidar nunca la lectura, entró en contacto con la vida bohemia de la capital, continuando su formación a través de la asistencia a las salas de conciertos, iniciándose además en la vida amorosa y en los juegos de seducción, uno de los aspectos igualmente contemplados en la Bildung de la época, unos años que coinciden con la era del jazz, que según Francis Scott Fitzgerald, se inició el 1 de mayo de 1919.20

Pues bien, su familia - después de verse obligada a abandonar Alsacia- se asentó en la población de Elbeuf, a orillas del Sena y en las cer-

\footnotetext{
${ }^{17}$ Honoré de Balzac, Fisiología del matrimonio (Barcelona: Ediciones Petronio, 1971), 339.

${ }^{18}$ André Maurois, Balzac (Barcelona: Salvat, 1985), 122.

${ }^{19}$ Maurois, Tierra de promisión, 137.

${ }^{20}$ Reinhart Koselleck, «Sobre la estructura antropológica y semántica de Bildung», en Historias de conceptos. Estudios sobre semántica y pragmática del lenguaje político y social (Madrid: Editorial Trotta, 2012), 49-93.
} 
canías de Ruan donde cursó los estudios de bachillerato, en una especie de paraíso perdido en medio del «reino de la lana» que había sustituido la antigua nobleza por una nueva clase industrial, la aristocracia lanera. ${ }^{21}$ No por azar, Maurois se sintió cercano a Marcel Proust, a quien dedicó un libro que rastrea aquel otro paraíso perdido en el que, entre otros aspectos, analiza su paso por el liceo y el regimiento, dos de las más genuinas instancias educativas republicanas. ${ }^{22}$ "A la Recherche du Temps Perdu est le poème du Temps, qui ne peut être retrouvé que sous la forme de l'art». ${ }^{23}$ En rigor, Balzac y Proust siempre formaron parte de su universo mental y literario.

De todos modos, y a pesar de la veneración de Maurois por Proust, surge entre ambos una diferencia notable, ya que si Proust fue un guerrero torpe no sucede lo mismo con Maurois, que siempre se mostró próximo a las virtudes militares, en especial a las dotes de mando de sus jefes. En vista de lo cual, en su pensamiento, la burguesía y la milicia comparten una misma preocupación, ya que como clases dirigentes deben saber mandar y dirigir el destino de un país como Francia.

Con este telón de fondo, y por lo que respecta a la vida sexual, procede señalar que también se integraba en los parámetros de la formación, sobre todo a partir de 1918 coincidiendo con el retroceso del puritanismo no sólo en Europa sino también en los Estados Unidos. Del mismo modo, la influencia del psicoanálisis obligaba a una revisión del tema del amor y, por ende, de las relaciones entre hombre y mujer, superándose hasta cierto grado las concepciones basadas en el eterno femenino que incidían en el mundo burgués del Romanticismo. Su propia vida no se entiende sin la presencia de la mujer, y así Dominique Bona, en su biografía sentimental sobre Maurois, no pierde de vista que en su caso coinciden tres elementos, a saber: la fábrica, la familia y la patria. ${ }^{24}$

\footnotetext{
${ }^{21}$ Maurois, El círculo de familia, 18.

${ }^{22}$ André Maurois, En busca de Marcel Proust (Barcelona: José Janés, editor, 1951).

${ }^{23}$ Maurois, Lettre ouverte à un jeune homme, 55.

${ }^{24}$ Dominique Bona, Il n'y a qu'un amour (Paris: Grasset, 2016 [première edition, mars 2003]). En concreto, nos referimos a la siguiente cita de este libro: «Usine, Famille, Patrie: la moral qu'on lui a inculquée ne laisse que peu de place â la rêverie et aux écarts de conduite» (p. 15). Sólo después de sus años de formación, y cuando abandonó la industria familiar, pudo dedicarse a la creación literaria.
} 
Con relación a su entorno femenino, hay que recordar a Jane-Wanda de Szymkiewicz (Janine), su primera esposa, de nacionalidad polaca y fe católica, con la que se casó el 30 de octubre de 1912 y de cuya unión nacieron una niña, Michelle, y dos varones, Gérald y Olivier. Janine que padecía una enfermedad neurológica, probablemente la neurastenia- era una mujer que precisaba de cuidados y sobre la que Maurois ejerció una notable influencia. A pesar de ello, vivió muchos meses separada de su esposo, movilizado durante la guerra del 14, circunstancia que no favoreció la fluidez conyugal. Ahora bien, Janine siempre se movió en ambientes lujosos como Deauville, situación que propició el alejamiento entre los esposos. «Il a épousé une jeune fille ravissante mais timide et, d'une certaine façon, inachevée». ${ }^{25}$ Según el mismo Maurois reconoce, Janine no pudo soportar la guerra. "Languideció y murió». ${ }^{26}$ Efectivamente, falleció el 26 de febrero de 1923 cuando esperaba un cuarto hijo.

A continuación, aparece el nombre de Simone de Caillavet, quien lo introdujo en los ambientes selectos parisinos y con la que se desposó el 6 de septiembre de 1926. "Janine avait le génie de l'amour, Simone aura celui de la patience». ${ }^{27}$ Simone, afectada por la anorexia y divorciada del rumano Georges Stoïcesco, era una intelectual que escribía poesía y mantenía una actitud librepensadora que facilitaba sus movimientos entre la alta sociedad parisina. "La mondanité est son sport préféré». ${ }^{28}$ Era madre de una hija - Françoise-Georgina, nacida a finales de 1920- de su primer matrimonio, con lo que la pareja formada por André y Simone acumulaban cuatro hijos. Al tiempo, Simone fue una fiel compañera y con ella compartió horas de trabajo, a la vez que le permitió disfrutar de la propiedad familiar de Essendiéras (Dordoña-Perigord), lugar de residencia del matrimonio Maurois durante la época estival y que, a la larga, se convirtió en «leur maison». ${ }^{29}$

Por último, hay que citar a la actriz chilena, nacida en 1914, María de los Dolores Checa García y Rivera, Marita, que fuera miss Pacífic en 1932 y que

\footnotetext{
${ }^{25}$ Bona, Il n'y a qu'un amour, 79.

${ }^{26}$ Suffel, André Maurois con notas de André Maurois, 32.

${ }^{27}$ Bona, Il n'y a qu'un amour, 293.

${ }^{28}$ Bona, Il n'y a qu'un amour, 201.

${ }^{29}$ Bona, Il n'y a qu'un amour, 252.
} 
se afincó en Perú. Como Maurois no hablaba español, Marita sirvió de intérprete durante la gira que nuestro autor efectuó por América en 1947. «Maria a vocation d'étoile». ${ }^{30}$ Además, Maurois quedó prendado de la sensualidad de una mujer gitana que le atraía físicamente. «Cette jeune femme incarne ce que Maurois aime: sa beauté, sa nature à la fois poétique et sensuelle, son sourire lumineux, sa grâce lascive, jusqu'à l'art de danser ou à celui de réciter des vers, lui plaisent aussitôt». ${ }^{31}$ Con ella mantuvo una aventura amorosa crepuscular en Lima aquel año 1947, que inspiró — después del monumental escándalo- la novela Las rosas de septiembre, escrita nueve años después y que dedicó a su esposa Simone. De tal guisa que, a pesar de este devaneo, Maurois luchó para mantener la felicidad conyugal, una de sus ideas-fuerza a partir de una concepción conciliadora de la vida que exige que el amor vaya acompañado por el deseo de felicidad. En consecuencia, el amor apasionado de los primeros momentos de la vida matrimonial ha de dar paso al amor conyugal, un amor sin estridencias que, sobre los principios de la estima y el mutuo reconocimiento, ha de procurar la paz conyugal. Incluso hacia el final de su vida, cuando ya había llegado a los ochenta años, dedicó al matrimonio diversas páginas de su Lettre ouverte à un jeune homme (1966), en que después de censurar el amor libre — «Rien n'est moins libre que l'amour libre» ${ }^{32}$ hace un elogio de la vía matrimonial que reclama cordura y paciencia con la mirada puesta en la conciliación.

Naturellement si la grande passion flambait déjà avant le mariage, il n'y a plus qu'à entretenir le feu. Mais si votre mariage a été fondé sur l'amitié, sur l'estime, alors apportez du petit bois: des attentions, de la gaieté, des goûts communs. Puis quand une jolie flamme claire commence de faire entendre son ronronnement, ne craignez plus rien. Alors les grosses bûches de la passion n'étoufferont plus ce foyer. Allumer un feu, qu'il s'agisse de l'âtre, de l'amour ou de la vocation, est un art qui demande adresse, attention et patience. ${ }^{33}$

En Climas (1928) se lee el siguiente texto, que suena a una auténtica declaración de principios: «Me parece que el amor ha de ser algo más

\footnotetext{
${ }^{30}$ Bona, Il n'y a qu'un amour, 357.

${ }^{31}$ Bona, Il n'y a qu'un amour, 358.

${ }^{32}$ Maurois, Lettre ouverte à un jeune homme, 109.

${ }^{33}$ Maurois, Lettre ouverte à un jeune homme, 156.
} 
grande que esa guerra cruel entre amantes». ${ }^{34}$ En definitiva, Maurois se manifiesta contrario al libertinaje, al donjuanismo y al amor venal aunque, sin desdeñar la castidad, opta sin ambages por el matrimonio, a la vez que repudia el aborto: «L'avortement est chose laide, contre nature». ${ }^{35}$

Además de elaborar una monografía sobre los diferentes tipos de amor —el amor caballeresco, el amor romántico, el amor-estrategia, el amor-pasión, el amor ideal y el amor físico, el amor evasión de Madame Bovary, etc.- Maurois constata que en el período de entreguerras las costumbres sociales habían cambiado radicalmente en París, coincidiendo con la llegada de los jóvenes americanos que, cargados de dólares, transformaron la capital francesa en una especie de prostíbulo de Europa. Así lo reflejó John Glassco en sus Memorias de Montparnasse: "Pero pronto me inicié en el aspecto más agradable de la prostitución, y disfruté de las delicias de esos servicios inspirados por el cielo, de este puerto y paraíso de los jóvenes, del burdel autorizado que era París». ${ }^{36}$ La literatura de Maurois también reflejó este ambiente y así en Climas (1928) -Isabelle, una de las protagonistas que reaparece en Tierra de promisión (1946)_ exclama: «Las costumbres de la posguerra eran muy libres». ${ }^{37}$

Como es lógico, Maurois no podía aceptar este estado de cosas - una Francia que caminaba hacia la disolución moral-, de modo que su interpretación discrepa de la que dio Glassco en sus Memorias. He aquí las consideraciones de Maurois:

Entre las dos guerras, de 1920 a 1940, vimos en París cómo un reducido núcleo de treinta o cuarenta personas alimentaba, con sus asuntos amorosos, toda la crónica escandalosa de la capital. El resto de la nación seguía llevando una vida normal, pero lo hacía sin ostentación ni algazara, en tanto que el pequeño grupo de cínicos daba pábulo a sensacionales informaciones en torno a sus aventuras. ${ }^{38}$

\footnotetext{
${ }^{34}$ André Maurois, Climas (Barcelona: Círculo de Lectores, 1980), 203.

${ }^{35}$ Maurois, Lettre ouverte à un jeune homme, 105.

${ }^{36}$ John Glassco, Memorias de Montparnasse (Madrid: Alfaguara, 2008), 121.

${ }^{37}$ Maurois, Climas, 129.

${ }^{38}$ André Maurois, «Siete aspectos del amor», Obras Completas. V (Barcelona: Plaza \& Janés, 1968), 632.
} 
Sirvan estos antecedentes para remarcar que la autoformación o educación de uno mismo (Selbstbildung), entendida como la formación completa del ser humano, reclamaba la presencia del otro sexo, con lo que el papel de la mujer adquiere una dimensión civilizadora de acuerdo con la tradición del eterno femenino. ${ }^{39}$ Quizás valga la pena recordar que en el tránsito del siglo XIX al Xx las cosas habían empezado a cambiar, con lo que retrocedía el puritanismo victoriano, un fenómeno no sólo inglés sino también continental. ${ }^{40}$ De tal suerte, y a modo de ilustración, se puede trazar una especie de itinerario imaginario que va del corsé al escote, según se desprende de la lectura de algunos cuentos de la neozelandesa Katherine Mansfield — cuya obra adquiere cada día mayor relieve-, ${ }^{41}$ que retrata el pulso de aquella época que gira en torno a las nuevas mujeres burguesas que frecuentaban los balnearios poco antes del estallido de la Primera Guerra Mundial y que vestían de una manera cada vez más deportiva y desenfadada.

Si el espíritu moderno aconsejaba que por razones higiénicas las mujeres no llevasen corsés, ya que constreñía el cuerpo e impedía la libertad de movimientos, de la misma manera en Inglaterra se había extendido el uso del escote, aspecto que no pasó desapercibido a Maurois. ${ }^{42}$ Con estos antecedentes se ponían en tela de juicio los viejos atavismos sexuales del puritanismo victoriano, facilitándose el flirt entre personas de diferente sexo que, además, podían compartir equipo en el juego del tenis. ${ }^{43}$ Por otra parte, Maurois detecta que en el tema de la mujer la situación ha evolucionado, y si antes la psicología tenía prioridad sobre la fisiología, con el paso del tiempo las cosas habían evolucionado en sentido inverso. Así, en la Lettre ouverte à un jeune homme (1966) reconoce que las modernas técnicas (inseminación artificial, anticonceptivos, etc.) permiten rectificar a la naturaleza, aspecto que no deja de preocuparle. Curiosamente, Maurois en aquella carta - y al lado de un gran número de escritores- cita únicamente a dos autoras, Katherine Mansfield y Virginia Wolf. ${ }^{44}$

\footnotetext{
${ }^{39}$ Koselleck, «Sobre la estructura antropológica y semántica de Bildung», 214.

${ }^{40}$ Peter Gay, Schnitzler y su tiempo. Retrato cultural de la Viena del siglo XIX (Barcelona: Paidós. 2002).

${ }^{41}$ Pietro Citati, La vida breve de Katherine Mansfield (Barcelona: Gatopardo Ediciones, 2016).

${ }^{42}$ Maurois, Tierra de promisión, 50.

${ }^{43}$ Katherine Mansfield, En un balneario alemán (Barcelona: Bruguera, 1981), 39 y 70.

${ }^{44}$ Maurois, Lettre ouverte à un jeune homme, 125, 127
} 
Así pues, pese a que la cuestión sexual fue tabú durante la Ilustración y buena parte del siglo XIX, empezó a circular una importante literatura libertina, que tiene en el Marqués de Sade un inequívoco punto de referencia, a la que siguieron diferentes títulos que servían de iniciación a la vida sexual. Aquí destaca con luz propia el nombre de la cantante de ópera Wilhelmine Shröder-Devrient, cuyas memorias — su autoría todavía hoy se discute- se editaron repetidamente a lo largo del siglo XIX, siendo vertidas al francés a comienzos del siglo pasado con un prólogo de Guillaume Apollinaire (1913). En suma, la cuestión sexual se hizo más patente después del regreso de los jóvenes de las trincheras. Para los soldados no había sido muy gratificante - como bien recuerda Erich Maria Remarque en Sin novedad en el frente (1929) — la experiencia de los prostíbulos. Al contrario, significaba algo sórdido, decadente y vejatorio para todos, prostitutas y soldados. Como es lógico, la sexualidad ocupó en toda Europa — sobre todo en la Alemania de la República de Weimar, circunstancia que favoreció la aparición de institutos científicos para el estudio de la cuestión - una centralidad desconocida, y se convirtió en un tema a debatir pedagógicamente después de que en muchos lugares se aceptara —no sin reticencias- la pedagogía de la aclaración o ilustración sexual y, a la vez, la coeducación. ${ }^{45}$

En cualquier caso, la formación exigía no solo el trato con personas del otro sexo, sino también profundizar en el funcionamiento de matrimonios que habían aceptado el engaño y el adulterio como moneda de cambio y que el retroceso del puritanismo obligó a revisar, lo cual favoreció la lenta y paulatina aceptación del divorcio. A partir de este momento, las relaciones entre personas de diferente sexo debían estar presididas por los sentimientos, más allá de las convenciones y, sobre todo, al margen de cualquier hipocresía, una rémora del pasado, del tiempo de la Belle Époque, del mundo anterior a la Gran Guerra (1914-1918) que vivía un aparente orden externo, pero con una manifiesta corrupción interna, esto es, una disolución de las costumbres que a la larga favoreció la desaparición del mundo de ayer. Por su lado, tal estado de cosas precipitó un nuevo orden moral, a raíz justamente del debilitamiento del puritanismo victoriano que, tal como hemos visto, incidía también en la Europa continental.

\footnotetext{
${ }^{45}$ Robert Beachy, Gay Berlín. Birthplace of a modern identity (New York: Alfred A. Knopf, 2014).
} 


\section{LOS AÑOS DE FORMACIÓN, ENTRE EL LICEO Y EL REGIMIENTO}

Como venimos señalando, Maurois formaba parte de una familia asentada en Francia desde hacía décadas, que, después de la emancipación de los judíos, había luchado por una asimilación que en su caso fue doble, no solo económico-industrial sino también cultural. Por aquel entonces, el caso Dreyfus - que influyó sobre Maurois durante sus años escolares- estaba a punto de estallar, tal como sucedió a finales de 1894 no cerrándose la cuestión hasta bien entrado el nuevo siglo (1906), con lo cual los intelectuales adquirieron una nueva responsabilidad en el concierto de la cultura europea. ${ }^{46}$

En el contexto revanchista del momento, no es de extrañar que su padre le contase episodios de la guerra franco-prusiana de 1870 y que le enseñara «a marcar el paso, al compás de canciones de marcha». ${ }^{47}$ Paradójicamente, la familia del capitán Alfred Dreyfus también procedía de Alsacia y prefirió instalarse en París, a fin de mantener sus vínculos con la naciente república que enlazaba con la tradición de la Revolución francesa de 1789. En relación con la situación de los judíos franceses, que en pocas horas se vieron forzados a depender del Segundo Imperio alemán, se ha escrito lo siguiente:

Entre ellos estaba la familia Dreyfus que, había llegado a París en 1871, aunque conservaba sus relaciones comerciales con Mulhouse. Eran patriotas franceses orgullosos, casi fanáticos. Alcanzar un grado en el ejército francés había sido la ambición infantil de Alfred Dreyfus».48

Entretanto, este apego a la carrera militar también se da en el caso de André Maurois, que fue educado según las costumbres de las familias judías asimiladas, compartiendo una formación políglota - pronto aprendió inglés y alemán- sin renunciar a los dos pilares del sistema educativo republicano francés, esto es, a la escuela y el ejército. Por ello, el padre de André Maurois - apasionado por las cuestiones militares- le introdujo junto a sus hermanos en el universo castrense: «Desde que pudimos sos-

\footnotetext{
${ }^{46}$ Antoni Martí Monterde y Bernat Padró Nieto (eds.), Qui acusa? Figures de l'intel-lectual europeu (Barcelona: Publicacions i edicions de la Universitat de Barcelona, 2015).

${ }^{47}$ André Maurois, «Ruan», en Obras Completas. IV (Barcelona: Plaza \& Janés, 1962), 947.

${ }^{48}$ Paul Johnson, La historia de los judios (Barcelona: Vergara, 2003), 460.
} 
tenernos sobre nuestras piernas, tanto mis hermanos como yo nos vimos obligados a caminar cantando canciones de marcha». ${ }^{49}$ De acuerdo con esta lógica, el padre le hizo aprender a montar a caballo, a fin de que algún día pudiese ser oficial de la reserva, una vieja tradición en la cultura continental europea, ya fuese prusiana, austriaca o francesa, en consonancia con el modelo escolar patriótico imperante desde el Congreso de Viena (1815).

No obstante, la familia de Maurois no estaba destinada a integrar la tropa del ejército francés, sino a mandar a los soldados de reemplazo. A estas alturas, el sueño kantiano de la paz perpetua se había esfumado, de modo que el padre de Maurois — que había sido suboficial—deseaba que su hijo alcanzase el grado de oficial. Según Dominique Bona «devoir et sacrifice» fue el santo y seña de la moral de la familia Herzog, ambiente que contrastaba con el de sus dos esposas Janine y Simone, mundanas y derrochadoras aunque ambas amantes de las costumbres inglesas. ${ }^{50}$

Tal como recordaba Emil Ludwig en 1939 —si bien refiriéndose a Prusia, pero el hecho se daba en buena parte del continente- «hombres de fama europea hacían imprimir en sus tarjetas de visita el título teniente de reserva, o se hacían llamar en casa por el mucamo: "Mi capitán" ".51 Mas, en realidad, la figura del oficial de complemento se da en toda Europa, y así Emilio Lussu — que tenía esta condición- dejó constancia de esta presencia en el ejército italiano, durante la Gran Guerra, en el libro Un anno sull'altipiano (1938). Así, muchos estudiantes que cursaban carreras de Letras en diversas universidades italianas se integraron en unidades de infantería durante la Primera Guerra Mundial. En consecuencia, el patriotismo de Maurois está fuera de toda duda y, después de ser movilizado como oficial de enlace durante la Gran Guerra, se presentó el 2 de septiembre de 1939 para que lo consideraran — a pesar de haber superado la edad- oficial de complemento, pasando a prestar sus servicios en el Comisariado de Información, dirigido por Jean Giraudoux. ${ }^{52}$ Posteriormente, y concluido el exilio en Nueva York entre 1940 y 1942,

\footnotetext{
${ }^{49}$ Maurois, Memorias, 22.

${ }^{50}$ Bona, Il n'y a qu'un amour, 228.

${ }^{51}$ Emil Ludwig, Tres dictadores: Hitler, Mussolini y Stalin. Y un cuarto: Prusia (Barcelona: Acantilado, 2011), 152.

${ }^{52}$ Maurois, Memorias, 330.
} 
volvió a ingresar en el ejército de la Francia libre cuando se produjo el desembarco aliado en el norte de África.

Naturalmente, en aquellos hogares europeos —sobre todo hebreos, como el de Maurois, Canetti o Proust- contaban con espléndidas bibliotecas que fomentaban la lectura entre los jóvenes de ambos sexos. Además, aquellas familias poseían unas madres cultivadas que compartían hábitos como la literatura y la música, asistían a las tertulias que se ofrecían en los salones los días de visita, de manera que los niños eran iniciados desde temprana edad en el mundo de las letras y de la cultura: «Mi madre —escribe Maurois- no sólo representó en mi vida un papel moral. A ella debo mi vocación literaria». ${ }^{53}$ De este modo, las bibliotecas de aquellas casas -repletas de volúmenes clásicos, a menudo ilustrados- se convertían en una especie de paraísos donde aquellos niños se introducían en el mundo de la aventura intelectual, con capacidad para encontrar incluso cosas raras y curiosas como hizo Descartes en La Flèche. No olvidemos, además, que los hijos de las familias judías francesas - lo mismo acontecía en el resto de Europa- eran altamente competitivos y siempre que podían sobresalían hasta alcanzar los lugares de honor. «Derrotaban constantemente a los franceses en su propio juego académico-cultural». ${ }^{54}$

Se trataba de una formación (Bildung) que respondía, empero, a los valores y principios del republicanismo francés, de modo que se distanciaba de las pretensiones de la formación prusiana que acabó pervirtiéndose en la Kultur germánica. ${ }^{55}$ Es cierto que coincidían en muchos puntos - la pasión por la literatura y la música, la afición por el teatro, el ideal de autoformación, el gusto por los viajes, el interés por las cuestiones científicas, un estilo de vida burgués y refinado, la sensibilidad estética, etc.—, pero no es menos verdad que el republicanismo galo — siempre atento a fin de no perder de vista los tres lemas de la Revolución, con la inclusión del principio de propiedad-se alejó del ultranacionalismo excluyente prusiano, gracias al principio de fraternidad universal. Sea como fuere, la vigencia de los planteamientos pedagógicos de Maurois llega hasta hoy mismo, ya que Un arte de vivir (1939) se completa con

\footnotetext{
${ }^{53}$ Suffel, André Maurois con notas de André Maurois, 28.

${ }^{54}$ Johnson, La historia de los judios, 458.

${ }^{55}$ Rosa Sala Rose, El misterioso caso alemán. Un intento de comprender Alemania a través de sus letras (Barcelona: Alba Editorial, 2007).
} 
la Lettre ouverte à un jeune homme (1966), un texto que conserva su actualidad.

Mientras la Bildung neohumanista inspirada en Goethe busca la eternidad, la vía formativa del republicanismo francés interpretada por Maurois, a la luz del magisterio de Alain, es menos metafísica ya que se circunscribe al ámbito de la vida cotidiana, al oficio de vivir, entendido como un arte de vivir, una vieja demanda clásica que en Francia se reavivó a partir de Rabelais y Montaigne. Es más, el oficio de vivir es visto como una especie de obra artesanal, como una forma de vida que adquiere por su dimensión poética el carácter de creación artística hasta configurar un arte de vivir. De todos modos, no podemos negar la influencia de Goethe en el pensamiento de Maurois, de quien resaltó su humanidad y la fuerza del eterno femenino, sin olvidar el sufrimiento que soportaron sus dobles (Werther, Meister, Fausto). ${ }^{56}$

Asimismo, y abundando en lo expuesto, constatamos que la obra novelada de Maurois también se puede abordar desde la perspectiva de la novela de formación (Bildungsroman). Tal situación se hace evidente en Climas (1928), cuando Philippe de Marcenat —una réplica del mismo Maurois- toma a su cargo la formación de Isabelle, personaje que recuerda a Simone, su segunda esposa, que de modo recíproco también influye sobre Philippe. Si en Climas recomienda la lectura de Stendhal, Proust y Merimée, Maurois elaboró su propio canon literario-formativo que abarca desde los griegos hasta los autores de su tiempo. En concreto, y sin más dilaciones, anotamos los siete escritores indispensables en la biblioteca de cualquier persona que desee formarse: Homero, Montaigne, Shakespeare, Balzac, Tolstoi, Proust y Alain. ${ }^{57}$

No hay que ser muy avispado para darse cuenta de que la relación que mantuvo André Maurois con Simone de Caillavet —su segunda esposa- recuerda la que describe en la segunda parte de Climas, al referirse a Isabelle:

Los libros que me daba para leer [se refiere a los que ofrecía Philippe de Marcenat a Isabelle, o, lo que es lo mismo, Maurois a Simone] me disgustaron al principio, pero no tardaron en gus-

\footnotetext{
${ }^{56}$ André Maurois, «Goethe», Obras Completas. V (Barcelona: Plaza \& Janés, 1968), 840-845.

${ }^{57}$ Maurois, Lettre ouverte à un jeune homme, 57.
} 
tarme, porque vi por qué le gustaban a él. Nada era tan fácil como comprender los gustos de Philippe; era uno de esos lectores que se buscan a sí mismos en los libros. ${ }^{58}$

Ese era, pues, Maurois, alguien que se buscaba a sí mismo a través del trato con los libros. No acaba aquí la cosa, porque si la Bildung propugna el alma bella del neoclasicismo de Schiller y Goethe (a pesar de las disonancias de Hölderlin y Nietzsche), el ideal formativo de Maurois fija su atención en el oficio de vivir, que también podría ser contemplado visto en su totalidad- como una autodidáctica artesanal. Sin embargo, y más que el alma bella, se postula la felicidad en un mundo que reclama la rehabilitación del humanismo después del desastre de la Gran Guerra, de las hecatombes del Marne (1914) y de Verdún (1916), en un contexto burgués que, además de promover una cultura del espíritu que combata el ambiente generalizado de crisis, aboga por la felicidad, proceso que se vivió en los años de entreguerras (1919-1939) pero que difícilmente trascendió a la fecha de 1945.

El reino intemporal de la literatura, que en parte sobrevivió al primer conflicto mundial — los bellos años de la postguerra (1918-1919), pueden considerarse como un último renacimiento de la felicidad y de la alegría de vivir-, este reino intemporal ya no sobrevivirá al segundo conflicto y al horror levantado por el descubrimiento de los campos de concentración. ${ }^{59}$

Sin embargo, y ante los embates de una juventud rebelde como la de los años sesenta, no dudó en escribir una brillante pieza pedagógica en la lettre d'apprentissage dirigida «à un jeune homme» (1966), que destila las mejores esencias pedagógicas de la literatura formativa emparentada con el oficio de vivir. Desde este prisma, el vitalismo de Maurois constituye una apuesta a favor de la esperanza y la acción en una época de crisis y desilusión, esto es, una invitación a la lucha —a nadar contracorrientepara alcanzar la felicidad que se conquista día a día, gracias a la acción continuada.

\footnotetext{
${ }^{58}$ Maurois, Climas, 135-136.

${ }^{59}$ Camille Bourniquel, Actitudes políticas del escritor francés contemporáneo (Madrid: Taurus, 1963), 21.
} 
Vistas así las cosas, es fácil comprender que cada instante de la vida haya que vivirlo como lo que es, aprovechando aquel momento como si se tratara de una pequeña creación poética de una larga sinfonía vital. Así, por ejemplo, Simona, uno de los personajes de su novela autobiográfica Bernad Quesnay (1926), año en que contrajo matrimonio con Simone de Caillavet, afirma - a modo de declaración programática- su intención de convertir en una obra de arte cada momento de su vida. ${ }^{60}$

Digamos de paso que Maurois comenzó interesándose por los estoicos «de quienes esperaba mucho y luego no recibí todo lo que yo esperaba». ${ }^{61}$ En el último tramo de su vida, reconocía que - pese a que continuaba leyendo autores como Epicteto y Marco Aurelio- no habían satisfecho sus expectativas. No compartía, pues, la resignación estoica porque «aceptar el mundo es renunciar a transformarlo, lo que, dentro de estrechos límites, es posible». ${ }^{62}$

Por su parte, la moral kantiana apenas le impresionó, aunque retuvo algunas hermosas fórmulas. En realidad, Maurois buscaba modelos concretos - personas de carne y hueso- que no aparecían en la deontología kantiana, siempre abocada al imperativo categórico en una especie de formalismo ético sin referentes ni ejemplos. Así se expresaba Maurois en 1963, cuatro años antes de su muerte:

Mi espíritu está hecho de tal manera que las expresiones abstractas apenas me conmueven. Necesito ejemplos concretos, un héroe y algo de poesía. Esto era lo que aportaba Alain. Le debo, no la moral clásica, pero sí la cristiana (comentaba admirablemente las parábolas) y la suya». ${ }^{63}$

Por supuesto que el espíritu de lucha, el ejercicio de la voluntad, fue la gran lección que Maurois aprendió junto a Alain, un espíritu radical y solitario. En efecto, Alain le formó con su ejemplo y le indicó que la felicidad es un deber, partiendo de la base de que la felicidad es una forma

\footnotetext{
${ }^{60}$ André Maurois, Bernard Quesnay (Barcelona: Destino, 1944), 67.

${ }^{61}$ Maurois, «Destinos ejemplares», 742.

${ }^{62}$ Suffel, André Maurois con notas de André Maurois, 244.

${ }^{63}$ Suffel, André Maurois con notas de André Maurois, 244.
} 
de amor donde el deseo se transforma en sentimiento. En cierto modo, la fórmula de Alain no era otra que "Quiero, luego existo», una corrección al racionalismo extremo cartesiano y al sentimentalismo romántico del «Deseo, luego existo». No es que Maurois denigre la razón y rechace el amor, sino algo muy distinto: sitúa la educación de la voluntad, gracias al primado de la acción, junto al cultivo de la inteligencia y del sentimiento que atempera el amor apasionado, causa de tantos fracasos matrimoniales.

El querer, pues, es prioritario si lo comparamos con el pensar y el desear. De aquí que Maurois no caiga en la abstracción de los valores etéreos y cosmopolitas que pivotan sobre los ideales de Humanidad (Lessing, Kant, Krause, Natorp), sino que encuentra en Alain, que observaba una sabiduría práctica, el modelo a seguir que orienta en los momentos de zozobra. «Un solo hombre en aquel tiempo comprendió lo que me sucedía. Fue Alain. A pesar de haber abandonado Ruan, continuaba siendo para mí, como para tantos otros, el maestro». ${ }^{64}$ Tanto es así que, con el paso de los años, Maurois fue elegido por los amigos y discípulos de Alain para pronunciar su elogio fúnebre ${ }^{65}$ La devoción por Alain fue de tal calibre que en Climas (1928) el hijo de Philippe de Marcenat e Isabelle se llamará Alain, el mismo nombre que debía llevar el que nació de la unión de Maurois con Simone de Caillavet: «Le 9 juin 1928, Simone accouche prématurément, d'un enfant mort-né: un fils. Il devait s'appeler Alain». ${ }^{66}$

Como es lógico deducir, desde temprana edad Maurois fue obsequiado por sus padres con libros de lecturas épicas que exaltaban las proezas militares en sintonía con el horizonte beligerante de una época en que los uniformes - ya fuese de tenientes o suboficiales- gozaban de gran prestigio: «El primer libro en el que aprendí a leer fue una historia de la guerra de 1870: Français et Allemands, de Dick Lonlay». ${ }^{67} \mathrm{Su}$ padre, pues, poseía en alto honor el mundo militar y así Maurois anotó en sus Memorias lo siguiente: «Fue el primero que me dijo: «Nosotros

\footnotetext{
${ }^{64}$ Maurois, Memorias, 102.

${ }^{65}$ Suffel, André Maurois con notas de André Maurois, 219-220.

${ }^{66}$ Bona, Il n'y a qu'un amour, 297.

${ }^{67}$ Maurois, Memorias, 22-23.
} 
tenemos en el ejército francés a un hombre genial: el teniente coronel Foch, quien me entregó los Principes de la Guerre en el momento en que fueron publicados». ${ }^{68}$

No en balde, el juego de los soldados de plomo era el elegido por los padres para comenzar la formación heroico-patriótica de unos jóvenes que, además de ser alistados en el ejército, deberían derramar su sangre por la patria, panorama que la pedagogía pacifista - liderada por Tolstoi, que participó como teniente de artillería en la guerra de Crimea- no dudó en criticar duramente. Aunque nunca fue partidario de la guerra, Maurois sintió atracción por la vida castrense, y, sobre todo, por determinados militares - Napoleón, Lyautey, Pétain, dejando a De Gaulle relegado a un segundo plano-, con lo que la inteligencia y la milicia, la pluma y las armas, se combinan en su caso de acuerdo con una cosmovisión republicana que sabe que la educación comienza en el hogar, continua en la escuela y culmina en el ejército. He aquí las secuencias de los años de aprendizaje que hay que seguir para poder dirigir la sociedad en tiempos críticos, ya sea en el ámbito civil (industrial, empresarial, comercial), político (prefectos, funcionarios) o militar (en una Francia que mantiene su pugna con Alemania y que, a la vez, posee un extenso imperio colonial). En su opinión, el ejército francés - a las puertas de la Gran Guerra- representaba una de las instituciones más prestigiosas, a pesar de la crisis desencadenada por el caso Dreyfus:

Poseía bellas tradiciones procedentes del antiguo régimen, del Imperio y de las guerras coloniales. Era en Francia una de las raras instituciones que hubiesen franqueado el puente de la revolución. Formados en escuelas inteligentes, sus oficiales alcanzaban en su mayor parte en su juventud un nivel de inteligencia y cultura muy honroso. Muchos de ellos llegaban al ejército, como más tarde lo describe Lyautey, llenos de una fe mística, casi religiosa. ${ }^{69}$

De ahí, pues, que la milicia adquiera - como se ve en el caso del mariscal Hubert Lyautey- una dimensión pedagógica, con lo que maestros y militares configuran un conjunto de perfiles que siempre estarán

\footnotetext{
${ }^{68}$ Maurois, Memorias, 27.

${ }^{69}$ Maurois, Memorias, 85.
} 
presentes en las obras literarias de Maurois. En verdad, no extraña que en diversos pasajes de sus obras plasmase emotivos recuerdos para sus maestros, en especial para los que profesaban en el liceo, primero en el Petit Lycée de Elbeuf, en el que ingresó a la edad de 8 años, y más tarde - a partir de los 12- en el Lycée Corneille de Ruan, del cual el primero era una filial. En Climas (1928) pone en boca de Philippe de Marcenat -una especie de alter ego de Maurois— las siguientes palabras: «Me gustaba mucho la vida del Liceo». ${ }^{70}$

Maurois destaca los méritos de Kittel que, además de confiar en el pequeño alumno, le sumergió en el mundo de las letras: «me inculcó el respeto a la lengua y me enseñó tan sólidamente los rudimentos del latín que con él todo me ha parecido fácil». ${ }^{71}$ Está claro que Kittel representa la imagen del profesor francés, leal a los principios de la Tercera República, que siempre tuvo bien presente lo que había significado la mutilación del territorio nacional a raíz de la derrota de Sedán (1870), que en opinión de Maurois fue un síncope.

Estos maestros de primera enseñanza no tenían otra ambición que la de formar, como mejor pudieran, las generaciones sucesivas de los jóvenes franceses. Se entregaban a esta tarea con tal pasión que les producía un vivo sufrimiento el perder a sus alumnos a la cancelación de cada curso. La víspera de la distribución de premios, Kittel nos leyó La Dernière Classe, de Alphonse Daudet. Le costó gran trabajo terminar su lectura. Lloraba, y los sollozos entrecortaban su voz. ${ }^{72}$

Ahora bien, el gran descubrimiento de aquellos años no tuvo lugar en Elbeuf sino en Ruan, a donde se trasladaba diariamente en viaje de ida y vuelta para acudir al liceo de la ciudad. El respeto y reconocimiento hacia sus profesores es tan manifiesto que en su escrito sobre Ruan da a conocer - emulando a Marco Aurelio, a quien acude a menudo a pesar de sus críticas a los estoicos- lo que debía a cada uno de sus maestros. Nos encontramos ante un verdadero elogio de sus

\footnotetext{
${ }^{70}$ Maurois, Climas, 16.

${ }^{71}$ Maurois, Memorias, 43.

${ }^{72}$ Maurois, Memorias, 43.
} 
mentores. A Nebout, profesor de segundo, le reconoce su afición por los románticos. A Texcier, profesor de Retórica, su apego por Voltaire, a quien dedicó una biografía.

A Lecaplan, profesor de Física, le debo cuanto sé acerca de las ciencias. Explicaba un curso excelente, en el que sólo se tenía en cuenta lo esencial [...]. A Mouchel, a Lelieuvre, ambos matemáticos, les debo la afición por los términos bien definidos y el horror hacia la elocuencia.

A Pichon, profesor de Gimnasia, le debo mi respeto por los movimientos bien ejecutados, con las puntas de los pies alargadas, descansando el peso sobre las muñecas y elevándolo por medio de imperceptibles tracciones. A Chartier [Alain], profesor de Filosofía, se lo debo todo. ${ }^{73}$

En cierto sentido, la figura de Alain —un radical admirador de Jules Ferry- se convirtió, ante los ojos de Maurois, en el maestro pensador de aquel mundo republicano, que también se encontraba en las provincias periféricas, ya fuesen agrarias o industriales, siempre alejadas de la capital. Ruan - la ciudad en que enseñaba Alain antes de trasladarse a París, donde continuó ejerciendo en el liceo Enrique IV, el de más prestigio de Francia- confirma cuanto decimos. En fin, a los ojos de Maurois - siempre atraído por Proust- Ruan aparece como una especie de mundo originario, casi paradisíaco, en cuyo liceo alcanzó un buen nivel de formación y en el que destacaba - con luz propia - la poderosa voz de Alain: "Cuando me encontraba demasiado triste trataba de evocar aquella vida dulce, los sueños del estudio, la clase de Chartier, los paseos de los filósofos - grupo de los estudiantes de los últimos cursos-, bajo los castaños del patio de los mayores». ${ }^{74}$

Las referencias de Maurois a Alain son constantes. «Fue en la clase de Chartier donde por vez primera, el aire fresco de la vida real penetró en nuestro mundo escolar». ${ }^{75}$ Además, en sus recuerdos escolares de los

\footnotetext{
${ }^{73}$ Maurois, «Ruan», 951-952.

${ }^{74}$ Maurois, «Ruan», 970.

${ }^{75}$ Maurois, «Ruan», 952.
} 
años pasados en el liceo de Ruan, Maurois comenta el siguiente hecho que marcó su vida:

Tenía dieciséis años cuando encontré al Hombre, pues así era como le llamábamos. En aquella mañana de octubre de 1901, en la que esperábamos, por primera vez a nuestro profesor de filosofía [...]. Entró con paso rápido y firme. Durante un momento, nos miró sin hablar; después, cogiendo un pedazo de tiza escribió en la pizarra dos frases de Platón: «Hay que ir a la verdad con toda el alma», y, «Hay que escoger el camino más largo». ${ }^{76}$

Después de leer estas dos frases escritas en griego sobre el encerado, el adolescente Maurois sintió un efecto fascinador, una especie de metanoia, hasta el extremo de reconocer que a partir de este momento le cambió la vida. ${ }^{77}$ Seis años después de que Maurois conociese a Alain, en 1907, este último empezó a escribir las notas — no más de dos páginas de papel de carta- que dieron lugar a los Propos sur le bonheur (1928), libro que proclama que la felicidad es un deber. La filosofía de Alain —vitalista y optimista- puede ser vista también como una alternativa al pensamiento neorromántico, es decir, al pesimismo de Schopenhauer y al nihilismo de Nietzsche. El 8 de septiembre de 1910, Alain había anotado la siguiente reflexión:

Se debería enseñar a los niños el arte de ser feliz. No el arte de ser feliz cuando la desgracia se desploma sobre nosotros; dejo eso para los estoicos; sino el arte de ser feliz cuando las circunstancias son tolerables y toda la amargura de la vida se reduce a pequeños contratiempos y malestares. ${ }^{78}$

Por si fuera poco, «el deber de ser feliz» — tan alejado de la moral deontológica kantiana, con su carga pietista - se articula como un principio vital que no acaba con uno mismo, sino que también se proyecta hacia los demás. "Insisto en que ser feliz es un deber hacia los demás». ${ }^{79}$ La cosa llega al extremo de que Alain sugiere, incluso, "una especie

\footnotetext{
${ }^{76}$ Maurois, «Destinos ejemplares», 769.

${ }^{77}$ André Maurois, «Alain», Obras Completas. V (Barcelona: Plaza \& Janés, 1968), 90.

${ }^{78}$ Alain, Sobre la felicidad (Madrid: Alianza Editorial, 1966), 211.

${ }^{79}$ Alain, Sobre la felicidad, 215.
} 
de corona cívica para premiar a los hombres que se propusieran ser felices» ${ }^{80}$ Por su lado, Maurois en la Lettre ouverte à un jeune homme (1966) deja bien claro que «l'objectif, c'est aussi d'être heureux». ${ }^{81}$

Por ello, no extraña que Alain —que había leído un centenar de veces la Comedia humana de Balzac, obra que comentaba a menudo y que influyó en Maurois, quien también desea retratar una especie de galería de personajes- propusiese que el ser humano tiene la obligación de jurar ser feliz y, a su vez, la necesidad de repudiar todo cuanto nos conduzca a la infelicidad. De hecho, Alain — discípulo de Jules Lagneau, profesor de filosofía en el liceo Michelet- es presentado por Jacques Suffel, biógrafo de Maurois, como un pensador republicano y liberal, celoso defensor de los derechos del hombre y contrario al poder omnímodo de la tiranía. ${ }^{82}$ En fin, Alain decidió ser feliz y, simultáneamente, que lo fuesen sus alumnos desde una posición crítica proclive a la acción, que entroncaba con la filosofía cartesiana de la duda, sin olvidar la dimensión dialógica socrática. «Su método era, más bien, enseñarnos a dudar». ${ }^{83}$

Todo indica que Alain —que centraba su saber en unos pocos libros, una treintena a lo más- nunca quiso renunciar a ejercer este magisterio, quizás al margen del academicismo al uso, tal como se desprende de la siguiente anécdota:

Un día, Rabier, Director de Enseñanza Secundaria, llegó de improviso, en el curso de una visita de inspección, en el momento en que nos estaba hablando de nuestros deberes acerca de las mujeres prostituidas. Tuvimos miedo ante la magnitud de la prueba que tenía que afrontar nuestro héroe. No cabe duda - pensamos - que ahora va a volver a referirse a Spinoza, a Platón. Pero cuando todos se hubieron sentado, Chartier continuó tranquilamente: «Estaba explicando a estos señores sus deberes acerca de las mujeres prostituidas...». Gran lección para aquellos jóvenes ruaneses. ${ }^{84}$

\footnotetext{
${ }^{80}$ Alain, Sobre la felicidad, 215.

${ }^{81}$ Maurois, Lettre ouverte à un jeune homme, 47.

${ }^{82}$ Suffel, André Maurois con notas de André Maurois, 207.

${ }^{83}$ Maurois, «Destinos ejemplares», 769.

${ }^{84}$ Maurois, «Ruan», 952-953.
} 
Además, Alain — para quien la inmoralidad más grande residía «no en la prostitución del cuerpo, sino en la de los sentimientos»— ${ }^{85}$ entendía la docencia de la filosofía a modo de una cruzada pedagógica, cosa lógica si tenemos en cuenta que confiaba en la educación:

Alain está lejos de despreciar la educación. Frecuentemente describe el animal humano, sombrío y presto a encabritarse cuando alguien se le acerca sin precauciones. La educación es una rara virtud que protege al espíritu, como nos lo recuerda el doble sentido de la palabra espíritu. El verdadero espíritu no hiere. En el arte de pensar hay siempre educación. ${ }^{86}$

Este sentido pedagógico de Alain —que desde una posición radical escribía en la prensa local de Ruan y dirigía debates en la Universidad popular - confiere a su filosofía una perspectiva educativa, con la intención de restaurar una cultura del espíritu de sesgo humanista sin connotaciones teológicas, aunque abierta a un espiritualismo que debe muchas cosas al mensaje cristiano. En la Lettre ouverte à un jeune homme (1966), escrita pocos meses antes de su fallecimiento, Maurois dedica un capítulo al tema de la fe y recupera la definición de Alain sobre el particular. ${ }^{87}$ De ascendencia judía y cercano al protestantismo, Maurois muestra sus simpatías por la figura de Cristo que irradia un sentido moral ejemplar, alentado además por los vientos del Concilio Vaticano II (1962-1965): «Vous avez — recuerda al joven destinatario de su carta — le bonheur de vivre au Temps où se répand cette bonne nouvelle». ${ }^{88}$

En suma, esta atmósfera espiritualista no es exclusiva de Alain y de Maurois, ni tampoco de Francia, sino que se da en todo el continente europeo con autores tan destacados como Werner Jaeger y Ernst Robert Curtius, amén de otros nombres menores como Juan Estelrich, Paul Valéry y Hermann Keyserling. ${ }^{89}$ "La influencia de Alain sobre mis gustos

\footnotetext{
${ }^{85}$ Maurois, Memorias, 70.

${ }^{86}$ Maurois, «Alain», 130.

${ }^{87}$ Maurois, Lettre ouverte à un jeune homme, 157.

${ }^{88}$ Maurois, Lettre ouverte à un jeune homme, 160.

${ }^{89}$ Silvia Coll-Vinent, «Hacia un nuevo humanismo: Joan Estelrich, Paul Valéry y Hermann Keyserling y el periodismo europeo de los años 30», en Cosas vistas, cosas leídas. La edad de oro del periodismo en Cataluña, España y Europa, eds. Xavier Pla y Francesc Montero (Kassel: Edition Reichenberger, 2014), 83-105.
} 
literarios fue tan poderosa como su influencia en mis ideas».$^{90}$ En realidad, Maurois fue fiel a su maestro hasta el final, tal como recuerda en los comentarios que dedicó - a manera de contrapunto- a la biografía de Suffel:

Cada vez que iba a París, corría a la calle de Rennes, donde vivía entonces, o iba a esperarle en el Liceo Henri IV, y atravesábamos juntos el parque de Luxembourg. Seguí sus clases en el Collège Sévigné. Cuando se jubiló, enfermo, tomé la costumbre de visitarle en el Vésinet. Discípulo canoso, me complacía ir a esa casita, que era para mí uno de los altos lugares del espíritu, y sentarme frente al sabio. ${ }^{91}$

No en balde, Alain —seguidor de Sócrates- elaboró textos pedagógicos a manera de breves ensayos, sin una sistemática como sucede con toda su obra. En concreto, nos referimos a los Propos sur l'éducation (con un prólogo fechado el 6 de junio de 1921), que se han publicado con el anexo de la Pédagogie enfantine. ${ }^{92} \mathrm{~A}$ imagen y semejanza de Alain, también Maurois deseaba formar un público lector como hacían los maestros del sistema republicano francés, que Albert Camus exaltó en la figura de Louis Germain con ocasión de recibir el Premio Nobel (1957). Solo de esta forma se puede entender el ethos pedagógico republicano que Maurois concreta en los ejemplos de la historia, con lo que sus estudios biográficos e históricos adquieren una innegable connotación formativa.

Desde luego, los años de aprendizaje de Maurois marcaron su trayectoria personal e intelectual. De una constitución un tanto débil y enfermiza, aprovechó las clases de gimnasia para endurecer su cuerpo y así — después de liberarse de un corsé que le comprimía- siguió las enseñanzas de Picon — «profesor de Gimnasia, antiguo suboficial»— para obtener un premio.

Todos los años, el Ministerio de la Guerra ofrecía al liceo una medalla para el alumno más destacado en gimnasia del estable-

\footnotetext{
${ }^{90}$ Maurois, Memorias, 63.

${ }^{91}$ Suffel, André Maurois con notas de André Maurois, 218-219.

${ }^{92}$ Alain, Propos sur l'éducation suivis de Pédagogie enfantine (Paris: Presses Universitaires de France, 1986). Hay traducción: Charlas sobre educación, seguido de Pedagogía infantil (Buenos Aires: Editorial Losada, 2002).
} 
cimiento [...]. Cuando, a fin de año, se celebró el concurso, obtuve mi medalla entre todos los gimnastas del Liceo. Me proporcionó más alegría que mi éxito en el bachillerato. ${ }^{93}$

Aquí conviene añadir que los años de formación de Maurois no sólo tomaron una dimensión intelectual en la que Alain tuvo un especial relieve, ya que gracias a su magisterio revisó a Sócrates, Descartes, Kant, Comte, Balzac y a otros autores más, sino que también se orientaron hacia la milicia, una vocación que se fraguó en el domicilio familiar y en las clases de gimnasia del liceo y que le llevó hasta el ejército, a los 18 años, como voluntario. Lógicamente, la vida francesa de aquel entonces no puede entenderse sin el recuerdo de las guerras napoleónicas y la crisis ocasionada por la caída del Segundo Imperio, con una verdadera «debacle» militar como Sedán (1870). En todo caso, y gracias a su interés por la gimnasia, fue declarado útil para el servicio militar:

Alimentado por mi padre y mis dos tíos con relatos militares; lector apasionado durante toda mi infancia de los libros guerreros de Danrit, y, desde hacía ya algunos años, de Vigny, de Stendhal y de Napoleón, hubiera considerado una desgracia no poder ser soldado. ${ }^{94}$

Por su parte, en Climas (1928), al tratar los años de aprendizaje de Philippe de Marcenat - retrato inspirado en apuntes autobiográficos y en las relaciones con sus dos esposas Janine y Simone, transformadas en Odile e Isabelle - rememora los juegos bélicos que entonces estaban en boga, sin mayores complicaciones:

Este juego había sido inspirado por la lectura de mi libro favorito: Guerre en Forteresse, de Danrit. En mi madriguera de francotirador, era Mitour el soldado de segunda, defendía el fuerte de Liouville, al mando de un viejo coronel por quien hubiera dado la vida muy gustoso. ${ }^{95}$

Por estas razones, ambos caminos - la cultura y la milicia, las letras y las armas, sin olvidar las ciencias- se darán en el pensamiento de

\footnotetext{
${ }^{93}$ Maurois, Memorias, 56.

${ }^{94}$ Maurois, Memorias, 76.

${ }^{95}$ Maurois, Climas, 15.
} 
Maurois en perfecta simbiosis, sin detectarse ningún tipo de contradicción, porque al fin y al cabo ambos aspectos - escuela y cuartel, liceo y regimiento- aparecen como las auténticas condiciones de posibilidad del ethos republicano. Más todavía, el ejército significó para Maurois una escuela de compañía, con lo que se acentuaba el deseo de asimilación de aquellos judíos que confiaban - a pesar de la crisis derivada del affaire Dreyfus - en la fortaleza de la Tercera República. No acaba aquí la cosa, porque si los sectores progresistas se pusieron del lado del capitán Dreyfus, los núcleos realistas católicos — buena parte de los cuales había aceptado a regañadientes el sistema republicano- se opusieron a las medidas contra la escuela confesional de la Tercera República. En concreto, la enemiga de los sectores conservadores se dirigió contra la política anticlerical del primer ministro francés Émile Combes (1902-1905), que llevó a cabo el cierre de las escuelas religiosas en manos de las congregaciones, un auténtico escándalo para las derechas, aspecto que Maurois reflejó en Tierra de Promisión (1946).

También hay que tener en cuenta que si con el caso Dreyfus el prestigio del ejército quedó un tanto dañado, Maurois hizo todo lo posible para que recuperase la reputación de antaño, en un momento en que, si por un lado se asistía al fin de la Belle Époque - y todo cuanto representaba-, por otro marcaba el punto álgido de la colonización francesa en África y en Asia: «Desde 1900, y sobre todo desde el affaire Dreyfus, la misión del artista o del escritor se ha oficializado, secularizado, normalizado, en relación a su época. La literatura entera ha entrado en el ámbito nacionalizado». ${ }^{96}$ Maurois intentaba, pues, establecer puentes con el mundo anterior a la crisis que siguió a la Gran Guerra, con aquella Belle Époque de un mundo de seguridades en franco retroceso, que el famoso J'accuse de Zola, del 13 de enero de 1898, puso en entredicho. Mientras Zola se enfrenta con el ejército, Maurois intenta salvar el honor de una institución que se vio salpicada por un escándalo que dividió Francia en dos bandos: los dreyfusards y los antisemitas, los defensores del capitán Dreyfus y los partidarios de la razón de estado. Con este telón de fondo, es fácil comprender que Maurois decidiese enaltecer la tradición militarista francesa que, en definitiva, pudo parar los pies en Verdún (1916)

\footnotetext{
${ }^{96}$ Bourniquel, Actitudes políticas del escritor francés contemporáneo, 17.
} 
al ejército prusiano, el mejor de cuantos existían a comienzos del siglo pasado. ${ }^{97}$

A la altura de los años veinte, Francia vivía en carne propia los desastres de la guerra con una inflación galopante, después de los sacrificios de muchas familias que vieron morir a padres, esposos y hermanos, sin olvidar que las mujeres también perdieron la guerra, según reflejó Curzio Malaparte en su teatro al recrear escenas de la vida de Viena en la primavera de 1945. ${ }^{98}$ Los motines de las tropas francesas — que aplacó Pétain no siempre con métodos ortodoxos- afectaron negativamente la imagen de un ejército que identificó la batalla de Verdún con las Termópilas, con la correspondiente dosis de simbolismo pedagógico para las nuevas generaciones que mantenía vivo el modelo escolar patriótico que Berta von Suttner había denunciado en ¡Abajo las armas! (1889) y que le valió el Premio Nobel de la Paz en 1905.

Como es natural, después de la revolución soviética de 1917 y del movimiento espartaquista en la Alemania de 1919, Francia precisaba de un ejército reconocido e identificado con los intereses del pueblo. Pero las tensiones continuaron y las diferencias entre De Gaulle y Pétain se hicieron en 1940 bien evidentes, marcando el destino dual de Francia, dividida entre la colaboracionista de Vichy y la Francia libre que inició su singladura desde las ondas radiofónicas londinenses.

Aparte de que Maurois ya contaba con una innegable vocación militar, su paso por el ejército fue una experiencia impagable. Además de conocer a otros jóvenes que procedían del ámbito de la cultura como el filósofo Étienne Gilson, o bien a algunos vástagos de las clases industriales, la vida castrense no le defraudó. Muy al contrario:

Del mismo modo que había amado la vida del liceo, amaba también la del regimiento. Toda una parte de nuestra existencia era todavía vida de estudiantes. Varios oficiales nos daban clases [...]. Fue para mí muy pronto un placer deportivo e intelectual participar en la escuela de compañía». ${ }^{99}$

\footnotetext{
${ }^{97}$ Paul Jankowski, Verdún 1916. Crónica de la batalla más célebre de la Primera Guerra Mundial (Madrid: La esfera de los libros, 2016).

${ }^{98}$ Curzio Malaparte, También las mujeres perdieron la guerra (Madrid: Ediciones Alfil, 1963).

${ }^{99}$ Maurois, Memorias, 78.
} 
Su interés fue tal que alcanzó el primer lugar de su pelotón, obteniendo los galones de sargento, graduación que mantenía cuando sonó la movilización a comienzos de agosto de 1914. El hecho de no ser todavía oficial —en su día olvidó cursar la solicitud para ser promovido a teniente- le salvó de una muerte casi segura en las trincheras durante la Gran Guerra, siendo destinado — gracias a su conocimiento de la lengua y cultura inglesas - como enlace con las tropas británicas. Finalmente, logró la graduación de capitán, con la que también fue movilizado en las trágicas horas de la primavera de 1940, cuando se produjo —en palabras de Marc Bloch — ${ }^{100}$ la extraña derrota de Francia, un desastre sobre el cual Maurois reflexionó profundamente. Está claro que para nuestro autor la cultura sin la fuerza militar no tiene sentido, de modo que fueron las luchas entre los políticos franceses las que impidieron la modernización del ejército, a la vez que en Francia se abría un divorcio entra las élites y el régimen republicano, situación que se agravó con la llegada del Frente Popular en 1936. ${ }^{101}$ De cualquier modo, en 1943, regresó del exilio - período en que fue objeto de una campaña de difamación, al ser acusado de partidario de Pétain- ${ }^{102}$ para ingresar por cuarta vez en el ejército francés.

\section{Nota sobre los autores:}

Raquel de la ARAda Acebes es profesora del Departamento de Teoría e Historia de la Educación de la Facultad de Educación de la Universidad de Barcelona. Se ha especializado en la historia de género y en la presencia de la mujer en las esferas públicas y privadas durante la edad contemporánea. Ha publicado diversos artículos en revistas histórico-pedagógicas y ha colaborado en diferentes obras colectivas sobre historia de la educación. Participa como docente en el Máster de Educación Secundaria en la Universidad de Barcelona.

\footnotetext{
100 Marc Bloch, La extraña derrota: testimonio escrito en 1940 (Barcelona, Crítica, 2003).

${ }^{101}$ André Maurois, Tragedia en Francia (Barcelona: Editorial Lara, 1944), 157-158.

102 Bona, Il n'y a qu'un amour, 388.
} 
JoRdi GARCIA FARRERo es profesor del Departamento de Teoría e Historia de la Educación de la Facultad de Educación de la Universidad de Barcelona y consultor en el grado de Educación Social de la Universitat Oberta de Catalunya (UOC). Premio Extraordinario de Doctorado por la Universidad de Barcelona (curso 2012-2013). Autor del libro Caminar. Experiencias y prácticas formativas (2014). Miembro del GREPPS (Grupo de Investigación en Pensamiento Pedagógico y Social) de la Universidad de Barcelona.

Conrad Vilanou Torrano es profesor del Departamento de Teoría e Historia de la Educación de la Facultad de Educación de la Universidad de Barcelona que se ha especializado en el estudio de los conceptos, discursos y narrativas pedagógicas. Director de la revista Temps d'Educació, que edita el Instituto de Ciencias de la Educación de la misma Universidad. Investigador principal del GREPPS (Grupo de Investigación en Pensamiento Pedagógico y Social), de la Universidad de Barcelona, grupo reconocido y consolidado por la Generalitat de Catalunya. Ha dirigido 33 tesis doctorales, tres de las cuales han obtenido el correspondiente Premio Extraordinario. 